\title{
Diaphragmatic herniation after esophagogastric surgery: systematic review and meta-analysis
}

\author{
Davide Bona ${ }^{1} \cdot$ Francesca Lombardo ${ }^{1} \cdot$ Kazuhide Matsushima ${ }^{2} \cdot$ Marta Cavalli $^{3} \cdot$ Valerio Panizzo $^{1} \cdot$ Paolo Mendogni $^{4}$. \\ Gianluca Bonitta ${ }^{1} \cdot$ Giampiero Campanelli $^{3}$. Alberto Aiolfi ${ }^{1}$ (D)
}

Received: 2 April 2021 / Accepted: 23 May 2021 / Published online: 15 June 2021

(C) The Author(s) 2021

\begin{abstract}
Introduction The anatomy of the esophageal hiatus is altered during esophagogastric surgery with an increased risk of postoperative hiatus hernia $(\mathrm{HH})$. The purpose of this article was to examine the current evidence on the surgical management and outcomes associated with $\mathrm{HH}$ after esophagogastric surgery for cancer.

Materials and methods Systematic review and meta-analysis. Web of Science, PubMed, and EMBASE data sets were consulted. Results Twenty-seven studies were included for a total of 404 patients requiring surgical treatment for $\mathrm{HH}$ after esophagogastric surgery. The age of the patients ranged from 35 to 85 years, and the majority were males (82.3\%). Abdominal pain, nausea/ vomiting, and dyspnea were the commonly reported symptoms. An emergency repair was required in $51.5 \%$, while a minimally invasive repair was performed in $48.5 \%$. Simple suture cruroplasty and mesh reinforced repair were performed in $65 \%$ and $35 \%$ of patients, respectively. The duration between the index procedure and HH repair ranged from 3 to 144 months, with the majority (67\%) occurring within 24 months. The estimated pooled prevalence rates of pulmonary complications, anastomotic leak, overall morbidity, and mortality were $14.1 \%(95 \% \mathrm{CI}=8.0-22.0 \%), 1.4 \%(95 \% \mathrm{CI}=0.8-2.2 \%), 35 \%(95 \% \mathrm{CI}=20.0$ $54.0 \%)$, and $5.0 \%(95 \% \mathrm{CI}=3.0-8.0 \%)$, respectively. The postoperative follow-up ranged from 1 to 110 months $($ mean $=24)$ and the pooled prevalence of $\mathrm{HH}$ recurrence was $16 \%(95 \% \mathrm{CI}=13.0-21.6 \%)$.

Conclusions Current evidence reporting data for $\mathrm{HH}$ after esophagogastric surgery is narrow. The overall postoperative pulmonary complications, overall morbidity, and mortality are $14 \%, 35 \%$, and 5\%, respectively. Additional studies are required to define indications and treatment algorithm and evaluate the best technique for crural repair at the index operation in an attempt to minimize the risk of $\mathrm{HH}$.
\end{abstract}

Keywords Esophagectomy $\cdot$ Gastrectomy $\cdot$ Hiatus hernia $\cdot$ Trans-diaphragmatic herniation $\cdot$ Outcomes

Alberto Aiolfi

alberto.aiolfi86@gmail.com

1 Division of General Surgery, Department of Biomedical Science for Health, Istituto Clinico Sant'Ambrogio, University of Milan, Via Luigi Giuseppe Faravelli, 16, 20149 Milan, Italy

2 Division of Acute Care Surgery, LAC+USC Medical Center, University of Southern California, 2051 Marengo Street, IPT, C5L100, Los Angeles, CA 90033, USA

3 Department of Surgery, University of Insubria, Milan, Italy

4 Thoracic Surgery and Lung Transplant Unit, Fondazione IRCCS Ca' Granda Ospedale Maggiore Policlinico, University of Milan, Via Francesco Sforza, 35 Milan, Italy

\section{Introduction}

Esophagogastric surgery is the cornerstone for esophageal and gastric cancer. These consist of a demolitive stage with en bloc esophageal or gastric dissection, lymphadenectomy, and restoration of the alimentary tract [1-3]. After the procedure, the normal anatomy around the hiatus can be altered due to surgical maneuvers causing inadvertent injuries to the crural muscular fibers. Therefore, there is an increased risk of postoperative hiatus hernia $(\mathrm{HH})$ with herniation of the intra-abdominal viscera. The incidence of $\mathrm{HH}$ after esophagogastric surgery is not well described. A recent systematic review reports a postoperative $\mathrm{HH}$ incidence of $2.6 \%$ up to 32-month follow-up; however, because of the limited follow-up and the selection bias for some studies reporting data for only $\mathrm{HH}$ requiring surgical management, the actual incidence might be underestimated [4]. 
HH after esophagogastric surgery can cause severe lifethreatening complications and critical illnesses in a high percentage of the patients $[5,6]$. These patients with $\mathrm{HH}$ often present with acute symptoms onset related to strangulation, necrosis, and perforation of the herniated viscera. Symptomatic HH mandates a surgical intervention, including reduction of the herniated intra-abdominal viscera and concomitant cruroplasty to reduce the risk of future recurrences [7]. Current knowledge about incidence, risk factors, and related outcomes is only supported by retrospective studies. Therefore, contemporary evidence about presenting symptoms, timing for surgical repair, treatment strategies, related complications, recurrence, and postoperative mortality is puzzled and unsettled.

The aim of this systematic review and meta-analysis was to examine the current literature on the surgical management and outcomes associated with $\mathrm{HH}$ after esophagogastric surgery for cancer.

\section{Materials and methods}

\section{Search strategy}

A systematic review was performed according to the guidelines from the Preferred Reporting Items for Systematic Reviews and Meta-analyses checklist (PRISMA) [8] and Meta-analyses of Observation Studies in Epidemiology (https://www.editorialmanager.com/jognn/account/MOOSE. pdf). The literature search ended on March 15, 2021. An institutional review board approval was not required. The literature search was conducted independently by three authors (AA, GB, and FL) to identify the English-written published series on hiatus hernia after esophagectomy or gastrectomy for cancer. Web of Science, PubMed, and EMBASE data sets were consulted matching the terms "hiatus hernia," "esophagectomy," "esophageal resection," "gastrectomy," and "gastric resection," with "AND" and "OR." The references of each article were assessed to complete the research [9].

\section{Inclusion and exclusion criteria}

Inclusion criteria are as follows: (a) articles reporting outcomes for hiatus hernia after esophagectomy or gastrectomy for cancer; (b) English written; (c) papers with the longest follow-up or the largest sample size in case of articles published by the same study group or based on the same dataset. Exclusion criteria are as follows: (a) not English written; (b) articles not reporting any of the a priori defined primary outcomes; (c) articles describing outcomes for distal gastrectomy or atypical gastric resection; (d) case series and case reports with $<5$ patients.

\section{Data extraction}

Three authors (FL, CL, and AA) independently extracted data from eligible studies. Data extracted included study characteristics (first author name, year, and journal of publication), number of patients included in the series, time frame, clinical and demographic characteristics of patients' population, type of surgical procedure, and postoperative outcomes. Disagreements between authors were resolved by consensus; if no agreement could be reached, a fourth senior author (DB) made the decision.

\section{Quality assessment}

The quality of observational studies was independently assessed by three authors (AA, FL, and CL) with the Risk of Bias In Non-Randomized Studies (ROBINS-I) instrument [10]. Confounding, selection, classification, intervention, missing data, outcomes measurement, and reporting bias were considered. Each domain was estimated with "yes," "probably yes," "probably no," or "no," and studies were categorized as having low, moderate, serious, or critical risk of bias.

\section{Outcomes}

Primary outcomes include the following: overall complications and hospital mortality. Secondary outcomes are as follows: anastomotic leak, pulmonary complications, cardiovascular complications, conversion to open, reoperation, hospital length of stay (HLOS), and hernia recurrence.

\section{Statistical analysis}

We performed a random-effects frequentist meta-analysis. Binary outcomes were pooled using generalized linear mixed models with logit transformation $[11,12]$. The maximum likelihood estimator was used to estimate the between-study variance $\left(\tau^{2}\right)$ and the nonparametric bootstrap was used to calculate its bias-corrected and $95 \%$ confidence interval. The inverse-variance weighted random-effects frequentist meta-analysis was performed by conventional methods using DerSimonian-Laird estimator for estimate between-study variance $\left(\tau^{2}\right)$ [13] Clopper-Pearson 95\% confidence interval for an individual was computed [14]. Statistical heterogeneity was evaluated ( $\mathrm{I}^{2}$ index): value of $25 \%$ or smaller was defined as low heterogeneity, value between 50 and $75 \%$ as moderate heterogeneity, and $75 \%$ or larger as high heterogeneity $[15,16]$. Small study and publication bias effects were assessed by trim and fill funnel plot visual inspection and Egger tests [17-19]. The prediction interval for the treatment effect of a new study is calculated according to 
Borenstein et al. [20]. As the sample size is not the same in all studies, we gradually removed a small sample size to perform a sensitivity analysis to assess stability of results. Two-sided $\mathrm{p}$-values were considered statistically significant when $<0.05$. All analyses and graphical representations were carried out using $\mathrm{R}$ version 3.2.2 software [21].

\section{Results}

\section{Systematic review}

Twenty-seven studies published between 1999 and 2021 met the inclusion criteria (Fig. 1). Overall, 23 studies reported data for the total number of surgical procedures performed for esophageal gastric cancer $(18,125$ patients). The prevalence of post-esophagogastric surgery $\mathrm{HH}$ was $3.18 \%$, while the prevalence of $\mathrm{HH}$ requiring surgical treatment was $2.01 \%$. Overall, 404 patients underwent surgical treatment for $\mathrm{HH}$ and were included in the final quantitative analysis. The sample size of the individual studies ranged from 5 to 43 . All reports were observational cohort studies. Fourteen studies were classified with moderate risk of bias, while thirteen had serious risk of bias at quality assessment (Supplementary Table 1). Patient demographics, clinical, and operative variables are shown in Table 1. The age of the included patients ranged from 35 to 85 years, the majority were males (82.3\%), and the preoperative body mass index (BMI) was reported in 10 articles. Overall, 21 studies (289 patients) described the surgical approach for the index operation: $57.0 \%$ had a hybrid or totally minimally invasive esophagectomy, $21.2 \%$ open esophagectomy, $15.2 \%$ transhiatal esophagectomy, and $6.6 \%$ total gastrectomy. The incidence of $\mathrm{HH}$ after minimally invasive procedures ranged from 0.0 to $22.1 \%$, while it ranged from 0.0 to $12.3 \%$ following open surgery. The pooled incidence of $\mathrm{HH}$ was higher after minimally invasive procedures $(5.3 \% ; 95 \% \mathrm{CI}=2.9-6.7)$ compared to open surgery $(1.5 \%$; $95 \% \mathrm{CI}=0.4-2.2)$.

Seventeen studies reported the details of the surgical technique for crural dissection at the index operation. The crural or diaphragmatic opening was not routinely performed, and the decision was left to the operating surgeon's preference. Partial or complete division of the right/left crus or dissection of the anterior aspect of the diaphragm was described and reported heterogeneously. Similarly, various techniques for hiatus closure at the index procedure were described in 14 studies (leaving the hiatus open, systematic hiatus closure with interrupted sutures, or simple closure reinforced with pledgets). Finally, 11 studies described the technique for diaphragmatic gastric tube fixation. Again, the reported techniques were variable (i.e., "a la demande" interrupted stitches, cardinal interrupted stitches at the 9,12, and 3 o'clock, continuous suture).
Preoperative symptoms related to $\mathrm{HH}$ were reported in 21 studies $(\mathrm{n}=329)$ : commonly reported symptoms were abdominal pain $(54.7 \%)$, nausea/vomiting $(33.4 \%)$, and dyspnea (24\%), while $15.5 \%$ were asymptomatic. Various indications for surgical repair of $\mathrm{HH}$ were reported, dependent on surgeon preference and hospital inclination. The majority of patients had involvement of the left hemithorax $(89.1 \%)$, while $3.4 \%$ had bilateral visceral herniation. The most commonly reported herniated organ was the colon $(51 \%)$, followed by combined colon-jejunum $(31 \%)$ and small bowel $(16 \%)$. The timing from the index procedure to diagnosis and surgical repair was specified in 19 studies and ranged from 3 to 144 months. The majority of patients $(67 \%)$ underwent surgical treatment within 24 months from the index cancer surgery. An emergency repair was performed in $51.5 \%$ of patients for incarceration or strangulation of the herniated viscera. Minimally invasive laparoscopic repair was successfully performed in $48.5 \%$ of patients. After reducing the herniated organs, simple suture cruroplasty was performed in $64.6 \%$, while mesh reinforced repair was necessary in $35.4 \%$ of patients. Other techniques such as pexy (colopexy, gastropexy, omentopexy) and crural gastric conduit fixation were reported in a minority of patients. Bowel resection was necessary for $6.9 \%$. The postoperative follow-up was reported in 15 studies and ranged from 1 to 110 months $($ mean $=23.7)$.

\section{Meta-analysis}

\section{Primary outcomes}

In addition to a systematic review, we performed a frequentist meta-analysis. Considering random-effects model, the estimated pooled prevalence of overall morbidity (16 studies, 300 patients) is $35 \%$ (95\% CI $=20.0-54.0 \%$ ) (Fig. 2A-B). The prediction lower and upper limits are $2.0 \%$ and $92.0 \%$, respectively. The heterogeneity index is high $\left(\mathrm{I}^{2}=69 \%, 95 \%\right.$ $\mathrm{CI}=59.6-95.7 \% ; \mathrm{p}<0.01)$. The sensitivity analysis shows the robustness of the results. The estimated pooled prevalence of hospital mortality ( 25 studies, 399 patients) is $5.0 \%$ (95\% $\mathrm{CI}=3.0-8.0 \%$ ) (Fig. 3A-B). The prediction lower and upper limits are $3.0 \%$ and $8.0 \%$, respectively. The heterogeneity index is $0\left(\mathrm{I}^{2}=0.0 \%, 95 \% \mathrm{CI}=0.0-8.4 \% ; \mathrm{p}=0.54\right)$. The sensitivity analysis shows the robustness of the results.

\section{Secondary outcomes}

The estimated pooled prevalence of anastomotic leak (17 studies, 335 patients) is $1.4 \%$ (95\% CI $=0.8-2.2 \%$ ). The prediction lower and upper limits are $0.3 \%$ and $4.3 \%$, respectively. The heterogeneity index is moderate $\left(\mathrm{I}^{2}=31 \%\right)$. The sensitivity analysis shows that omitting the study by Gust et al., the heterogeneity decreases to $0.0 \%$. The pooled prevalence of cardiovascular complication (14 studies, 283 patients) is 


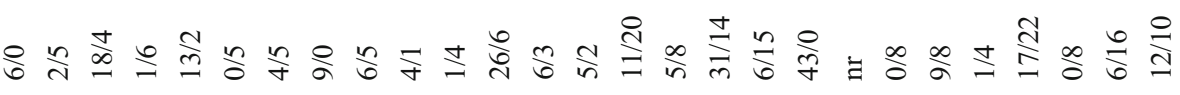

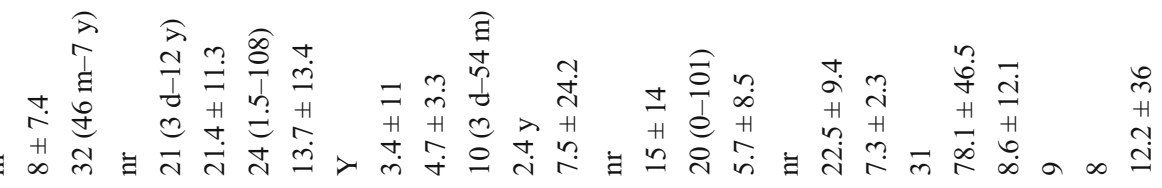

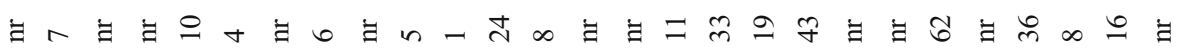

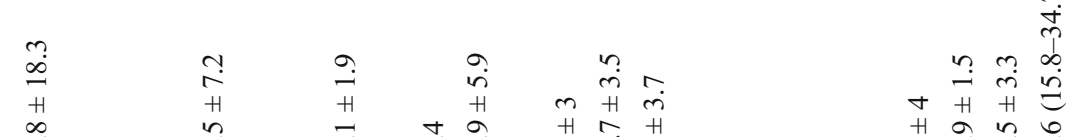

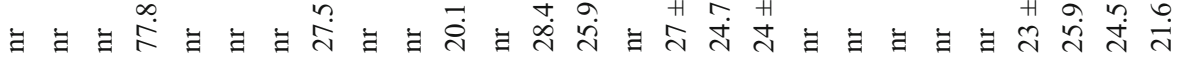

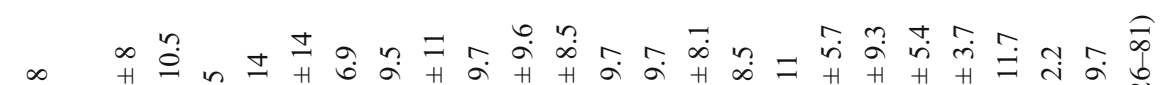

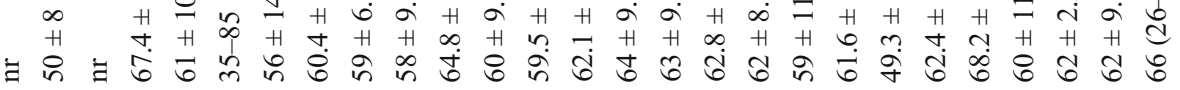

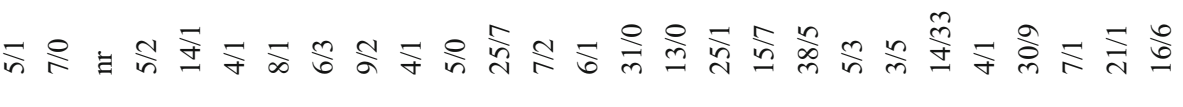
ดกสี

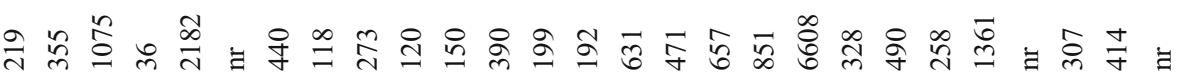

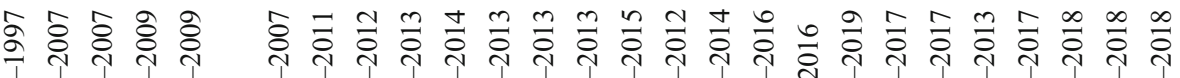

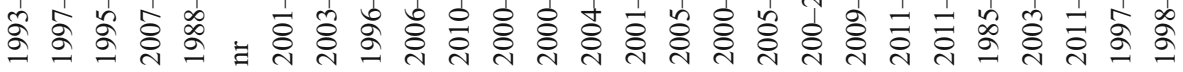

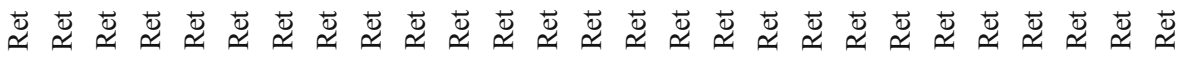
ปี

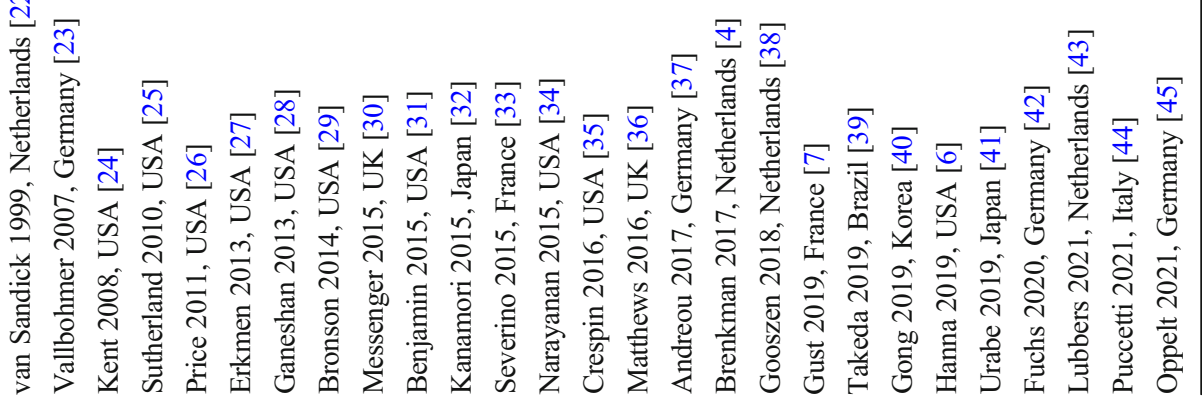


Fig. 1 The Preferred Reporting Items for Systematic Reviews and Meta-Analysis checklist (PRISMA) diagram
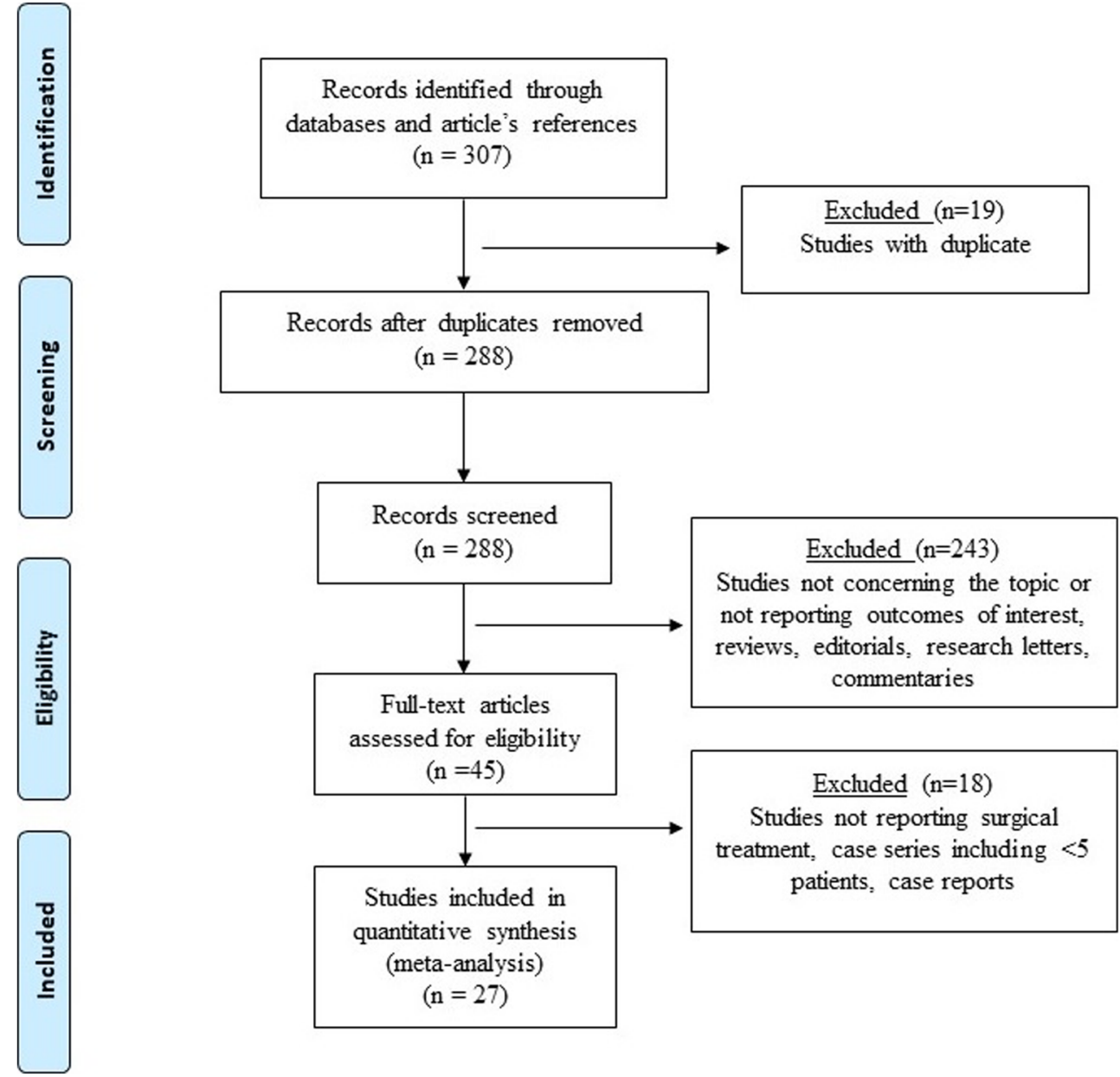

9.0\% (95\% CI $=4.1-16.0 \%)$ with a moderate heterogeneity $\left(\mathrm{I}^{2}=68 \%\right)$. The pooled prevalence of pulmonary complication (18 studies, 344 patients) is $14.1 \%(95 \% \mathrm{CI}=8.0-22.0 \%)$ with a moderate heterogeneity $\left(\mathrm{I}^{2}=27 \%\right)$. The pooled prevalence rates of conversion to open procedure (18 studies) and reoperation (22 studies) are 9.2\% (95\% CI $=4.0-21.0 \%)$ and $12.0 \%$ (95\% CI $=8.0-17.3 \%)$, respectively. The estimated pooled mean HLOS (16 studies) is 15.9 days $\left(\mathrm{I}^{2}=93 \%\right)$. The pooled prevalence of recurrence after HH repair (22 studies) is $16.0 \%\left(I^{2}=0.0 \%\right)$ (Table 2$)$.

\section{Discussion}

Our systematic review suggests that evidence reporting data for hiatus hernia after esophagogastric surgery is scarce and only supported by retrospective studies. In the present analysis, the incidence of post-esophagectomy/gastrectomy $\mathrm{HH}$ is about $3 \%$, while up to $2 \%$ of patients may require surgical treatment. Postoperative overall complications rate is up to $40 \%$, while anastomotic leak and pulmonary complications are commonly reported. The postoperative hospital mortality is estimated up to $5 \%$.
There is limited experience with trans-diaphragmatic visceral herniation after esophagogastric surgery even at highvolume centers, and current evidence is mainly ascribed to observational studies. The actual prevalence of transhiatal herniation after esophagogastric surgery is a matter of discussion, with previous studies reporting a wide range of incidence. This is likely due to the various definitions of diaphragmatic hernia and the heterogeneous inclusion criteria. All these issues, in conjunction with the retrospective design of studies, lack of adherence to standardized follow-up schedules, routine imaging, threshold for clinical suspicion, and presence of mild symptoms, may be responsible for the real prevalence of underreporting and underestimation [5, 36]. For example, Brenkman et al. reported a $\mathrm{HH}$ incidence of $7 \%$ after esophagectomy. This percentage was probably underestimated because up to $25 \%$ of patients that underwent esophagectomy did not undergo a computed tomography scan [3]. On the other hand, Ganeshan et al. reported a higher percentage of HH (up to $15 \%$ ) in their study, including both symptomatic and asymptomatic patients [28]. A recently published analysis reported a mean $\mathrm{HH}$ incidence of $2.6 \%$ during the postoperative follow-up to 32 months [31]. Similarly, in the present analysis, the incidence of $\mathrm{HH}$ has been estimated at around 
a

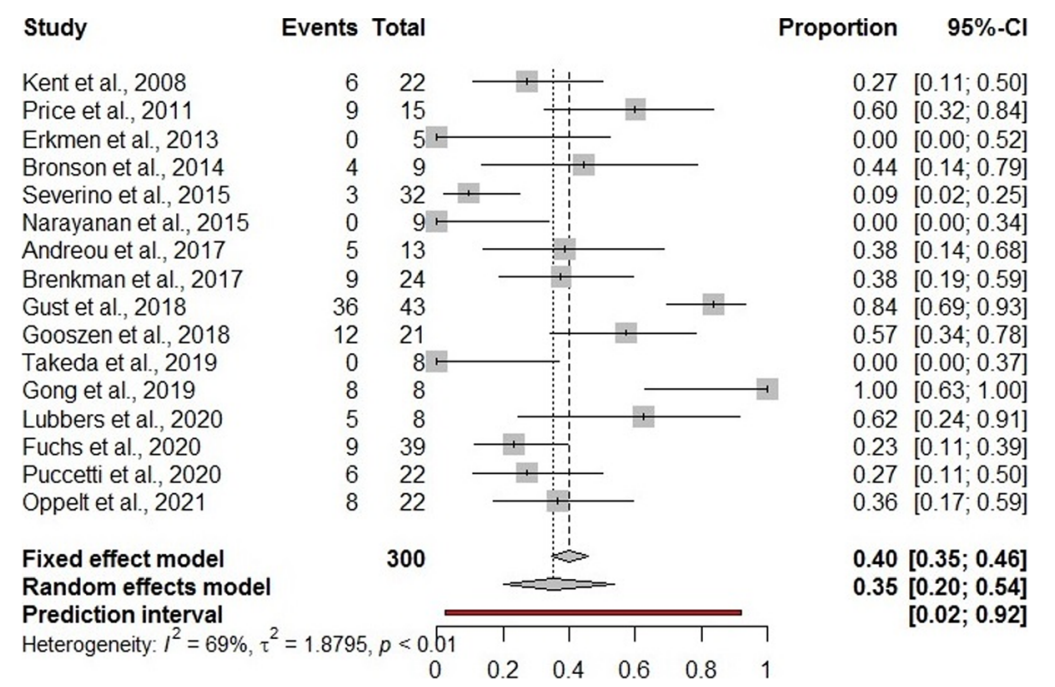

b

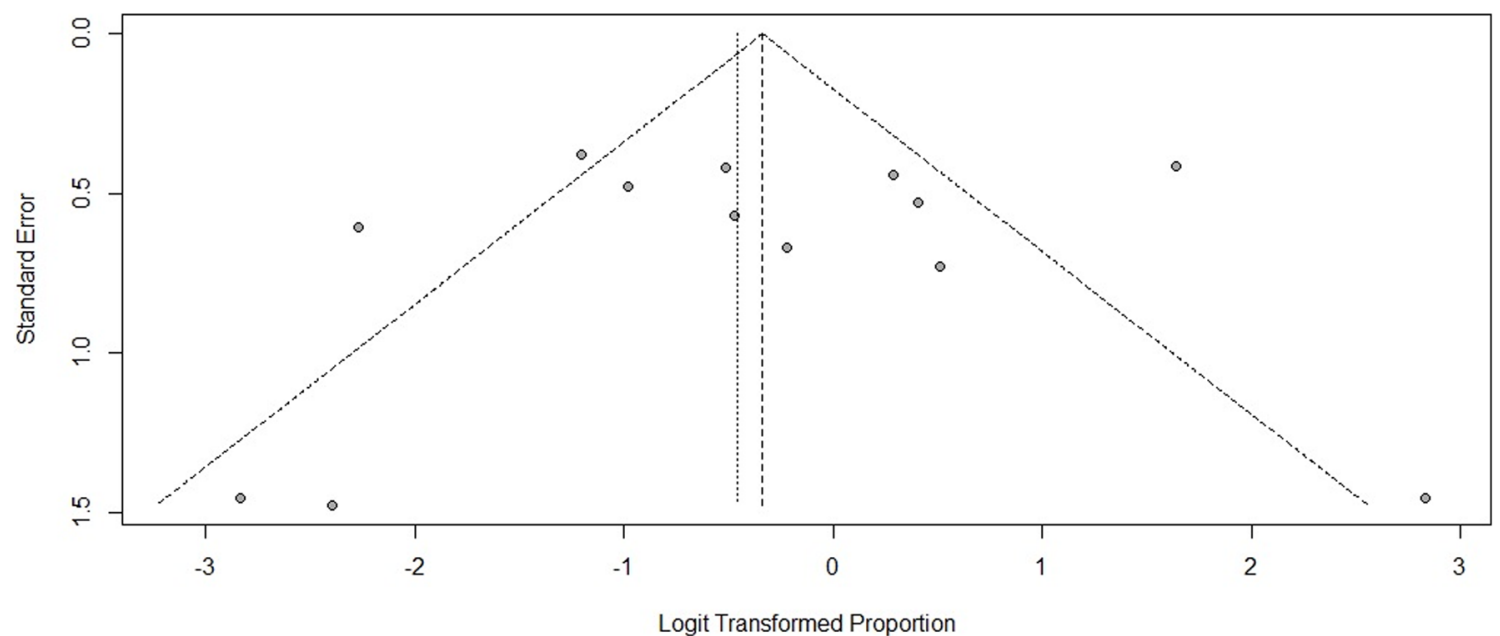

Fig. 2 Forest plot (A) and funnel plot (B) for overall complications

$3 \%$, with almost $2 \%$ of subjects requiring surgical repair. Although transhiatal herniation may develop in both open and minimally invasive procedures, we observed a trend toward a higher incidence of $\mathrm{HH}$ after minimally invasive surgery $(5.3 \%$ vs. $1.5 \%)$. This result is in line with previous studies reporting a significantly higher incidence of $\mathrm{HH}$ after minimally invasive surgery [5]. It has been proposed that decreased postoperative intra-abdominal adhesions and a larger size hiatal defect created by minimally invasive approaches are associated with a higher incidence of HH $[24,30]$. In contrast, other studies reported the use of a minimally invasive approach was not identified as an independent predictor for $\mathrm{HH}$ in the multivariate analysis [4]. Therefore, whether a minimally invasive approach would increase the risk of $\mathrm{HH}$ is still unclear. Symptomatic HH may occur both in the short- and long-term follow-up and will presumably become an increasing problem as cancer survival improves. In the present study, the timing of presentation ranged from 3 to 144 months, with the majority of patients (67\%) being diagnosed within 24 months from the index cancer procedure. This result supports the data reported by Brenkman et al. that described a higher risk of $\mathrm{HH}$ within the first 2 years from the index procedure [4].

The pathophysiology of diaphragmatic visceral herniation after esophagogastric surgery has been extensively discussed. As reported in previous studies, pre-existing hiatal hernia, surgical widening of the hiatus, accidental pleural laceration, advanced tumor stage with partial crural en bloc resection, and high abdominal-thoracic pressure gradient are risk factors. Additionally, lower BMI $\left(<25 \mathrm{~kg} / \mathrm{m}^{2}\right)$ or excessive weight loss after index surgery, diabetes, total number of harvested lymph nodes, transhiatal approach, and neoadjuvant therapy have been advocated as further risks [22-45]. In an attempt to restore the hiatus function and reduce the incidence of $\mathrm{HH}$, several technical features have been described such as direct closure of the diaphragmatic defect, crural mesh reinforcement, 
Fig 3 Forest plot (A) and funnel plot (B) for in-hospital mortality
Study

Events Total

Proportion

$95 \%-\mathrm{Cl}$

Sutherland et al., 1999

Vallbohmer et al., 2007

Kent et al., 2008

Price et al., 2011

Erkmen et al., 2013

Ganeshan et al., 2013

Bronson et al., 2014

Messenger et al., 2014

Benjamin et al., 2015

Kanamori et al., 2015

Severino et al., 2015

Crespin et al., 2015

Narayanan et al., 2015

Matthews et al., 2016

Andreou et al., 2017

Brenkman et al., 2017

Gust et al., 2018

Gooszen et al., 2018

Takeda et al., 2019

Gong et al., 2019

Hanna et al., 2019

Lubbers et al., 2020

Fuchs et al., 2020

Puccetti et al., 2020

Oppelt et al., 2021

Fixed effect model

Random effects model

Prediction interval

Heterogeneity: $I^{2}=0 \%, \tau^{2}=0, p=1.00$

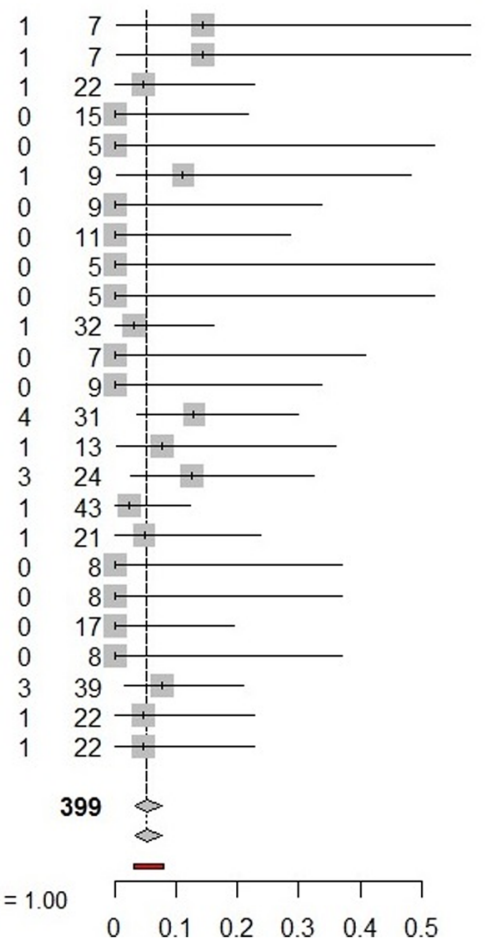

$0.14[0.00 ; 0.58]$

$0.14[0.00 ; 0.58]$

$0.05[0.00 ; 0.23]$

$0.00[0.00 ; 0.22]$

$0.00[0.00 ; 0.52]$

$0.11[0.00 ; 0.48]$

$0.00[0.00 ; 0.34]$

$0.00 \quad[0.00 ; 0.28]$

$0.00[0.00 ; 0.52]$

$0.00[0.00 ; 0.52]$

$0.03[0.00 ; 0.16]$

$0.00[0.00 ; 0.41]$

$0.00 \quad[0.00 ; 0.34]$

$0.13[0.04 ; 0.30]$

$0.08 \quad[0.00 ; 0.36]$

$0.12[0.03 ; 0.32]$

$0.02[0.00 ; 0.12]$

$0.05[0.00 ; 0.24]$

$0.00[0.00 ; 0.37]$

$0.00[0.00 ; 0.37]$

$0.00 \quad[0.00 ; 0.20]$

$0.00[0.00 ; 0.37]$

$0.08 \quad[0.02 ; 0.21]$

$0.05[0.00 ; 0.23]$

$0.05[0.00 ; 0.23]$

$0.05[0.03 ; 0.08]$

$0.05[0.03 ; 0.08]$

$[0.03 ; 0.08]$

\section{b}

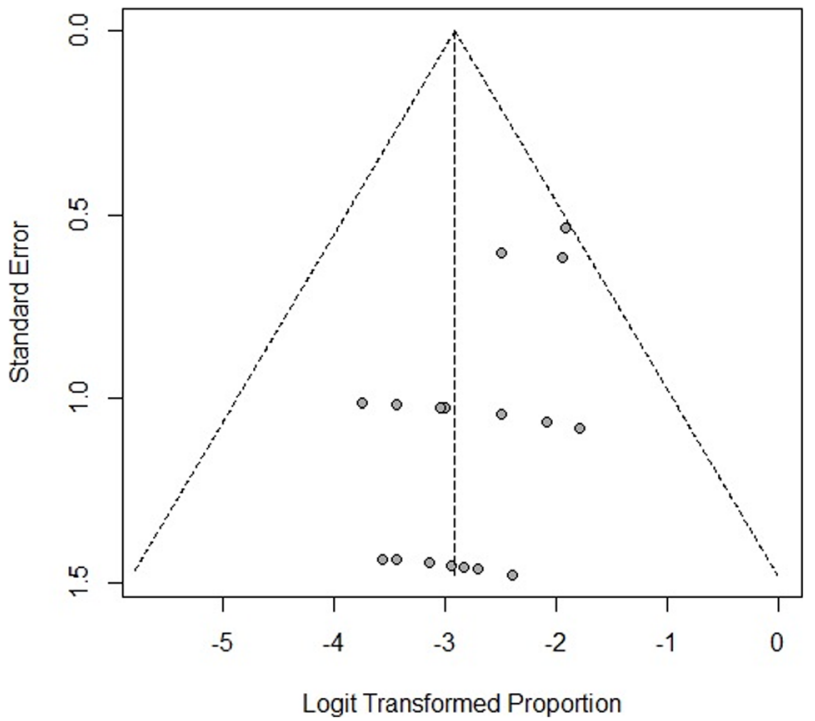

fixation of the conduit to the crura, and omentopexy at the index operation. However, data are sparse and conclusive evidence about the most appropriate technique for $\mathrm{HH}$ prevention is lacking. In the present systematic review, only 14 studies described the technique for crural reconstruction at the index procedure. Therefore, any attempt at quantitative analysis was not possible because data were heterogeneous and outcomes reported as aggregated. Further studies are necessary to assess the best technique for crural repair in attempt to minimize the risk of $\mathrm{HH}$ [46].

Abdominal pain, nausea/vomiting, and dyspnea were commonly reported. These symptoms should be always monitored carefully in patients with previous esophagogastric surgery as these can be signs of mild HH. Therefore, it is recommended to have a high index of suspicion for a prompt diagnosis $[4,6$, 47]. Dysphagia and weight loss were less frequently reported; 
Table 2 Secondary outcomes values are expressed as pooled proportions and $95 \%$ confidence intervals (95\% CI). $I^{2}$, heterogeneity; HLOS, hospital length of stay

\begin{tabular}{llll}
\hline Outcomes & Proportion (95\% CI) & $\mathrm{I}^{2}(95 \% \mathrm{CI})$ & No. of studies \\
\hline Cardiovascular complications & $9.0 \%(4.1-16.0 \%)$ & $68 \%(26-95 \%)$ & 14 \\
Pulmonary complications & $14.1 \%(8.0-22.0 \%)$ & $27 \%(5.3-49.0 \%)$ & 18 \\
Anastomotic leak & $1.4 \%(0.8-2.2 \%)$ & $31 \%(0.0-53.1 \%)$ & 17 \\
Reoperation & $12.0 \%(8.0-17.2 \%)$ & $0.0 \%(0.0-78 \%)$ & 22 \\
Conversion to open & $9.2 \%(4.5-21.0 \%)$ & $0.0 \%(0.0-67 \%)$ & 18 \\
Recurrence & $16.0 \%(13-22.6 \%)$ & $0.0 \%(0.0-26.1 \%)$ & 22 \\
HLOS (days) & $15.93(10.4-21.4 \%)$ & $93 \%(76.2-99.4 \%)$ & 16 \\
\hline
\end{tabular}

however, tumor recurrence should always be excluded in these patients. While symptomatic $\mathrm{HH}$ represents an absolute indication for surgical intervention, asymptomatic or mild symptomatic patients pose a dilemma for surgeons. A conservative wait-and-see approach in patients without symptoms has been proposed by some authors. In contrast, others recommended an elective surgical repair even in asymptomatic patients because of the subtle risk of hernia enlargement and possible evolution through complication $[6,26,42]$. Current evidence is narrow and heterogeneous, while a robust indication for conservative vs. operative treatment in asymptomatic or mild symptomatic patients with small- to medium-size hernia is still unsolved. Therefore, additional studies are required to better define a precise treatment algorithm in these patients. The decision should be patient tailored while "pros" and "cons" should be balanced and individualized according to prognosis, underlying diseases, and patient wishes.

Emergent or urgent repair may be required in the case of severe HH-related complications such as incarceration, ischemic bowel complications, strangulation, or bowel perforation $[28,48]$. In the present study, about $51 \%$ of patients underwent urgent/emergent repair and bowel resection was performed in about $7 \%$. To date, different types of operative strategies have been described. Both open and laparoscopic approaches have been advocated as safe and feasible options. However, surgeons should be prepared to undertake a thoracic approach in case of severe thoracic adhesions that prevent the reduction of the prolapsed contents into the abdominal cavity. During the operation, the viability of the herniated viscera should be evaluated and closure of the diaphragmatic defect is recommended to possibly reduce the risk of $\mathrm{HH}$ recurrence. While simple suture cruroplasty was performed in $65 \%$, mesh reinforced repair was adopted in $35 \%$ of patients. Currently, a definitive indication about the most appropriate technique for crural repair is lacking and further studies are warranted to deeply assess this issue.

Transhiatal herniation after esophagectomy and gastrectomy has been shown to be associated with non-negligible postoperative complications and mortality. The present quantitative analysis showed that the postoperative morbidity and mortality RR are 35\% (95\% CI $=20.0-54.0 \%)$ and $5.0 \%$ $(95 \% \mathrm{CI}=3.0-8.0 \%)$, respectively. While the heterogeneity for overall morbidity is high, thus probably reflecting different articles reporting and the definition of postoperative complications across studies, the related heterogeneity for postoperative mortality was $0.0 \%$, thus adding robustness to the result. These data seem similar to previous studies reporting postoperative morbidity and mortality rates up to $45 \%$ and $10 \%$ [22-45]. It has been reported that postoperative mortality may be higher in patients that presented with acute symptoms and required an emergent operation; however, a subgroup analysis including emergency cases was not feasible because the data were reported as aggregated. Interestingly, pulmonary complications $(\mathrm{RR}=$ $14.1 \%, 95 \% \mathrm{CI}=8.0-22.0 \%$ ) were the most commonly observed postoperative complications. Therefore, surgeons should be aware of these life-threatening complications that require prompt diagnostic workup and management. The pooled mean hospital length of stay was 15.9 days $(95 \% \mathrm{CI}=10.1-21.5)$ with high related heterogeneity $\left(\mathrm{I}^{2}=93 \%\right)$. This may be explained by several factors such as patients' age, comorbidities, preoperative BMI, surgical technique, need for visceral resection, hospital volume, and surgeons' expertise.

The postoperative follow-up ranged from 1 to 110 months. The estimated RR for recurrence was $16 \%$ (95\% CI). The related heterogeneity was high, thus probably reflecting the significant variability within surgical techniques for crural reconstruction, operating surgeon's expertise, and patients' comorbidities. Therefore, evidence to support one technique over another for crural repair and hiatus approximation is lacking, while future studies should focus on this issue to possibly minimize such complication.

We acknowledge that this review does have some limitations related to possible publication bias due to the exclusion of non-English articles, heterogeneity of some of the studies included, and retrospective nature of the included series. As a result of the retrospective design of included studies, lack of routine imaging, and short follow-up, the exact incidence of $\mathrm{HH}$ might be underreported. Various techniques for crural/ diaphragmatic dissection, crural approximation, and gastric tube fixation at the index operation were described. In 
addition, a specific surgical approach was usually chosen for each case based on the operating surgeon's preference and may represent a selection bias. Finally, the limited patient cohort may constitute a further limitation. However, it should be noted that $\mathrm{HH}$ after esophagogastric surgery is a relatively rare complication with few publications and limited patients' cohorts. Therefore, this meta-analysis aims to plea for further qualitative and standardized studies in order to codify the best surgical technique for hiatus closure at the index procedure, to further assess a precise indication about asymptomatic patients (conservative vs. surgery), and find out a universally accepted approach and treatment algorithm for such cases. Finally, future studies should be focused on the identification of predictive factors for $\mathrm{HH}$ in high-risk patients where preventive measures can be attempted and closer postoperative follow-up applied.

\section{Conclusions}

Current evidence reporting data for $\mathrm{HH}$ after esophagogastric surgery is limited and only supported by retrospective studies. While the actual incidence remains unknown, the present study demonstrates that the incidence of post-esophagectomy/gastrectomy $\mathrm{HH}$ is $3 \%$, while surgical management is necessary in about $2 \%$ of patients. The overall postoperative complications rate may occur in up to $35 \%$ of patients with pulmonary complications being commonly reported. The postoperative mortality is estimated up to $5 \%$. Additional studies are required to define indications and treatment algorithm and evaluate the best technique for crural repair at the index operation in an attempt to minimize the risk of $\mathrm{HH}$.

Authors' contributions AA, FL, MC, and VP did the literature search. $\mathrm{AA}, \mathrm{GC}$, and $\mathrm{DB}$ formed the study design. Data collection was done by AA, FL, PM, and MC. AA, KM, GB, and DB analyzed the data. AA, $\mathrm{KM}, \mathrm{GC}$, and $\mathrm{DB}$ interpreted the data. $\mathrm{AA}, \mathrm{KM}$, and $\mathrm{DB}$ wrote the manuscript. AA, KM, GC, and DB critically reviewed the manuscript.

Funding Open access funding provided by Università degli Studi di Milano within the CRUI-CARE Agreement.

\section{Declarations}

Conflict of interest The authors declare that there is no conflict of interest.

Ethical statement All procedures performed in studies involving human participants were in accordance with the ethical standards of the institutional and/or national research committee and with the 1964 Helsinki declaration and its later amendments or comparable ethical standards. This article does not contain any studies with human participants or animals performed by any of the authors.

Informed consent Informed consent does not apply.
Open Access This article is licensed under a Creative Commons Attribution 4.0 International License, which permits use, sharing, adaptation, distribution and reproduction in any medium or format, as long as you give appropriate credit to the original author(s) and the source, provide a link to the Creative Commons licence, and indicate if changes were made. The images or other third party material in this article are included in the article's Creative Commons licence, unless indicated otherwise in a credit line to the material. If material is not included in the article's Creative Commons licence and your intended use is not permitted by statutory regulation or exceeds the permitted use, you will need to obtain permission directly from the copyright holder. To view a copy of this licence, visit http://creativecommons.org/licenses/by/4.0/.

\section{References}

1. Omloo JM, Lagarde SM, Hulscher JB et al (2007 Dec) Extended transthoracic resection compared with limited transhiatal resection for adenocarcinoma of the mid/distal esophagus: five-year survival of a randomized clinical trial. Ann Surg 246(6):992-1000

2. Haverkamp L, Seesing MF, Ruurda JP, Boone J, V Hillegersberg R (2017 Jan 1) Worldwide trends in surgical techniques in the treatment of esophageal and gastroesophageal junction cancer. Dis Esophagus 30(1):1-7

3. Brenkman HJ, Haverkamp L, Ruurda JP et al (2016 Apr 21) Worldwide practice in gastric cancer surgery. World $\mathrm{J}$ Gastroenterol 22(15):4041-4048

4. Brenkman HJ, Parry K, Noble F et al (2017) Hiatal hernia after esophagectomy for cancer. Ann Thorac Surg 103(4):1055-1062. https://doi.org/10.1016/j.athoracsur.2017.01.026

5. Oor JE, Wiezer MJ, Hazebroek EJ (2016 Aug) Hiatal hernia after open versus minimally invasive esophagectomy: a systematic review and meta-analysis. Ann Surg Oncol 23(8):2690-2698

6. Hanna AN, Guajardo I, Williams N, Kucharczuk J, Dempsey DT (2020) Hiatal hernia after esophagectomy: an underappreciated complication? J Am Coll Surg 230(4):700-707. https://doi.org/10. 1016/j.jamcollsurg.2019.12.009

7. Gust L, Nafteux P, Allemann P, Tuech JJ, el Nakadi I, Collet D, Goere D, Fabre JM, Meunier B, Dumont F, Poncet G, Passot G, Carrere N, Mathonnet M, Lebreton G, Theraux J, Marchal F, Barabino G, Thomas PA, Piessen G, D'Journo XB (2019 Jun 1) Hiatal hernia after oesophagectomy: a large European survey. Eur J Cardiothorac Surg 55(6):1104-1112. https://doi.org/10.1093/ejcts/ ezy451

8. Moher D, Liberati A, Tetzlaff J et al (2009 21) Preferred reporting items for systematic reviews and meta-analyses: the PRISMA statement. PLoS Med 6(7):e1000097

9. Goossen K, Tenckhoff S, Probst P, Grummich K, Mihaljevic AL, Büchler MW, Diener MK (2018 Feb) Optimal literature search for systematic reviews in surgery. Langenbeck's Arch Surg 403(1): 119-129

10. Sterne JA, Hernan MA, Reeves BC et al (2016) ROBINS-I: a tool for assessing risk of bias in non-randomised studies of interventions. BMJ 355:i4919. https://doi.org/10.1136/bmj.i4919

11. Lin L, Chu H (2020 Sep) Meta-analysis of proportions using generalized linear mixed models. Epidemiology. 31(5):713-717

12. Schwarzer G, Chemaitelly H, Abu-Raddad LJ, Rücker G (2019 Sep) Seriously misleading results using inverse of FreemanTukey double arcsine transformation in meta-analysis of single proportions. Res Synth Methods 10(3):476-483

13. DerSimonian R, Laird N (1986) Meta-analysis in clinical trials. Control Clin Trials 7(3):177-188 
14. Ferrari D, Aiolfi A, Bonitta G, Riva CG, Rausa E, Siboni S, Toti F, Bonavina L (2018 Sep 12) Flexible versus rigid endoscopy in the management of esophageal foreign body impaction: systematic review and meta-analysis. World J Emerg Surg 13:42

15. Clopper CJ, Pearson ES (1934) The use of confidence or fiducial limits illustrated in the case of the binomial. Biometrika. 26(4):404 413

16. Aiolfi A, Asti E, Bonitta G, Bonavina L (2018 May) Esophagectomy for end-stage achalasia: systematic review and meta-analysis. World J Surg 42(5):1469-1476

17. Higgins JP, Thompson SG (2002) Quantifying heterogeneity in a meta-analysis. Stat Med 21:1539-1558

18. Anzures-Cabrera J, Higgins JP (2010) Graphical displays for metaanalysis: an overview with suggestions for practice. Res Synth Methods 1(1):66-80

19. Egger M, Davey Smith G, Schneider M et al (1997) Bias in metaanalysis detected by a simple, graphical test. BMJ 13;315(7109): 629-634

20. Borenstein M, Hedges LV, Higgins JPT, Rothstein HR (2009) Introduction to meta-analysis. John Wiley \& Sons, Ltd, Chichester, UK

21. R Development Core Team (2015) A language and environment for statistical computing. R Foundation for Statistical Computing, Vienna, Austria. isbn:3-900051-07-0

22. van Sandick JW, Knegjens JL, van Lanschot JJ, Obertop H (1999 Jan) Diaphragmatic herniation following oesophagectomy. Br J Surg 86(1):109-112. https://doi.org/10.1046/j.1365-2168.1999. 00979.x

23. Vallböhmer D, Hölscher AH, Herbold T, Gutschow C, Schröder W (2007 Dec) Diaphragmatic hernia after conventional or laparoscopic-assisted transthoracic esophagectomy. Ann Thorac Surg 84(6):1847-1852. https://doi.org/10.1016/j.athoracsur.2007. 07.009

24. Kent MS, Luketich JD, Tsai W, Churilla P, Federle M, Landreneau R, Alvelo-Rivera M, Schuchert M (2008) Revisional surgery after esophagectomy: an analysis of 43 patients. Ann Thorac Surg 86(3): 975-983. https://doi.org/10.1016/j.athoracsur.2008.04.098

25. Sutherland J, Banerji N, Morphew J, Johnson E, Dunn D (2011) Postoperative incidence of incarcerated hiatal hernia and its prevention after robotic transhiatal esophagectomy. Surg Endosc 25(5): 1526-1530. https://doi.org/10.1007/s00464-010-1429-8

26. Price TN, Allen MS, Nichols FC 3rd, Cassivi SD, Wigle DA, Shen KR, Deschamps C (2011 Dec) Hiatal hernia after esophagectomy: analysis of 2,182 esophagectomies from a single institution. Ann Thorac Surg 92(6):2041-2045. https://doi.org/10.1016/j. athoracsur.2011.08.013

27. Erkmen CP, Raman V, Ghushe ND, Trus TL (2013 Aug) Laparoscopic repair of hiatal hernia after esophagectomy. J Gastrointest Surg 17(8):1370-1374. https://doi.org/10.1007/ s11605-013-2246-x

28. Ganeshan DM, Correa AM, Bhosale P, Vaporciyan AA, Rice D, Mehran RJ, Walsh GL, Iyer R, Roth JA, Swisher SG, Hofstetter WL (2013) Diaphragmatic hernia after esophagectomy in 440 patients with long-term follow-up. Ann Thorac Surg 96(4):11381145. https://doi.org/10.1016/j.athoracsur.2013.04.076

29. Bronson NW, Luna RA, Hunter JG, Dolan JP (2014) The incidence of hiatal hernia after minimally invasive esophagectomy. J Gastrointest Surg 18(5):889-893. https://doi.org/10.1007/s11605014-2481-9

30. Messenger DE, Higgs SM, Dwerryhouse SJ, Hewin DF, Vipond MN, Barr H, Wadley MS (2015) Symptomatic diaphragmatic herniation following open and minimally invasive oesophagectomy: experience from a UK specialist unit. Surg Endosc 29(2):417-424. https://doi.org/10.1007/s00464-014-3689-1

31. Benjamin G, Ashfaq A, Chang YH, Harold K, Jaroszewski D (2015) Diaphragmatic hernia post-minimally invasive esophagectomy: a discussion and review of literature. Hernia. 19(4):635-643. https://doi.org/10.1007/s10029-015-1363-8

32. Kanamori J, Fujita T, Daiko H (2016) Diaphragmatic herniation after thoracolaparoscopic esophagectomy for carcinoma of the esophagus: a report of six cases. Esophagus 13:88-92. https://doi. org/10.1007/s10388-015-0485-5

33. Ulloa Severino B, Fuks D, Christidis C, Denet C, Gayet B, Perniceni T (2016) Laparoscopic repair of hiatal hernia after minimally invasive esophagectomy. Surg Endosc 30(3):1068-1072. https://doi.org/10.1007/s00464-015-4299-2

34. Narayanan S, Sanders RL, Herlitz G, Langenfeld J, August DA (2015) Treatment of diaphragmatic hernia occurring after transhiatal esophagectomy. Ann Surg Oncol 22(11):3681-3686. https://doi.org/10.1245/s10434-015-4366-x Epub 2015 Feb 24

35. Crespin OM, Farjah F, Cuevas C, Armstrong A, Kim BT, Martin AV, Pellegrini CA, Oelschlager BK (2016) Hiatal herniation after transhiatal esophagectomy: an underreported complication. J Gastrointest Surg 20(2):231-236. https://doi.org/10.1007/s11605015-3033-7

36. Matthews J, Bhanderi S, Mitchell H, Whiting J, Vohra R, Hodson J, Griffiths E (2016) Diaphragmatic herniation following esophagogastric resectional surgery: an increasing problem with minimally invasive techniques?: post-operative diaphragmatic hernias. Surg Endosc 30(12):5419-5427. https://doi.org/10.1007/ s00464-016-4899-5

37. Andreou A, Pesthy S, Struecker B, Dadras M, Raakow J, Knitter S, Duwe G, Sauer IM, Beierle AS, Denecke C, Chopra S, Pratschke J, Biebl M (2017) Incidence and risk factors of symptomatic hiatal hernia following resection for gastric and esophageal cancer. Anticancer Res 37(12):7031-7036. https://doi.org/10.21873/ anticanres. 12173

38. Gooszen JAH, Slaman AE, van Dieren S, Gisbertz SS, van Berge Henegouwen MI (2018) Incidence and treatment of symptomatic diaphragmatic hernia after esophagectomy for cancer. Ann Thorac Surg 106(1):199-206. https://doi.org/10.1016/j.athoracsur.2018. 02.034

39. Takeda FR, Tustumi F, Filho MAS, Silva MO, Júnior UR, Sallum RAA, Cecconello I (2020) Diaphragmatic hernia repair after esophagectomy: technical report and lessons after a series of cases. J Laparoendosc Adv Surg Tech A 30(4):433-437. https://doi.org/ 10.1089/lap.2019.0596

40. Gong CS, Ko CS, Kim BS, Kim HS (2019) Diaphragmatic hernia after totally laparoscopic total gastrectomy for gastric cancer. Surg Laparosc Endosc Percutan Tech 29(3):194-199. https://doi.org/10. 1097/SLE.0000000000000638

41. Urabe M, Haruta S, Ohkura Y, Yago A, Koga S, Tanaka T, Ueno M, Udagawa H (2019) Diaphragmatic herniation following total gastrectomy: review of the long-term experience of a tertiary institution. Langenbeck's Arch Surg 404(8):993-998. https://doi.org/10. 1007/s00423-019-01842-6

42. Fuchs HF, Knepper L, Müller DT, Bartella I, Bruns CJ, Leers JM, Schröder W (2020) Transdiaphragmatic herniation after transthoracic esophagectomy: an underestimated problem. Dis Esophagus 33(12):doaa024. https://doi.org/10.1093/dote/doaa024

43. Lubbers M, Kouwenhoven EA, Smit JK, van Det MJ (2021) Hiatal hernia with acute obstructive symptoms after minimally invasive oesophagectomy. J Gastrointest Surg 25(3):603-608. https://doi. org/10.1007/s11605-020-04745-w 
44. Puccetti F, Cossu A, Parise P, Barbieri L, Elmore U, Carresi A, De Pascale S, Fumagalli Romario U, Rosati R (2021) Diaphragmatic hernia after Ivor Lewis esophagectomy for cancer: a retrospective analysis of risk factors and post-repair outcomes. J Thorac Dis 13(1):160-168. https://doi.org/10.21037/jtd-20-1974 PMID: 33569196; PMCID: PMC7867823

45. Oppelt PU, Askevold I, Hörbelt R, Roller FC, Padberg W, Hecker A, Reichert M (2021) Trans-hiatal herniation following esophagectomy or gastrectomy: retrospective single-center experiences with a potential surgical emergency. Hernia. https://doi.org/10.1007/ s10029-021-02380-1

46. Bonavina L, Asti E, Sironi A, Bernardi D, Aiolfi A (2017) Hybrid and total minimally invasive esophagectomy: how I do it. J Thorac Dis 9(Suppl 8):S761-S772
47. Porta A, Aiolfi A, Musolino C, Antonini I, Antonio Zappa MA (2017) Prospective comparison and quality of life for single-incision and conventional laparoscopic sleeve gastrectomy in a series of morbidly obese patients. Obes Surg 27(3):681-687

48. Chirica M, Kelly MD, Siboni S, Aiolfi A, Riva CG, Asti E, Ferrari D, Leppäniemi A, Ten Broek RPG, Brichon PY, Kluger Y, Fraga GP, Frey G, Andreollo NA, Coccolini F, Frattini C, Moore EE, Chiara O, Di Saverio S, Sartelli M, Weber D, Ansaloni L, Biffl W, Corte H, Wani I, Baiocchi G, Cattan P, Catena F, Bonavina L (2019 May 31) Esophageal emergencies: WSES guidelines. World J Emerg Surg 14:26. https://doi.org/10.1186/s13017-019-0245-2

Publisher's note Springer Nature remains neutral with regard to jurisdictional claims in published maps and institutional affiliations. 